\title{
Human Capital Strategies to Reduce Employee Turnover in the Food Service and Automotive Industries
}

\author{
Olivia Patrice Chante' Miller ${ }^{1}$ and Regina Banks-Hall ${ }^{2}$ \\ ${ }^{1}$ Department of Business Administration, Catawba Valley Community College, Hickory, North Carolina, US \\ ${ }^{2}$ Department of Graduate \& Professional Studies, Cleary University, Howell, Michigan, US \\ *Correspondence: Olivia Patrice Chante’ Miller, oliviapcmiller@gmail.com
}

\begin{abstract}
High voluntary employee turnover in service industries often exceeds $60 \%$, negatively affecting profitability due to employee replacement costs. In studies conducted with multinational corporate leaders, they acknowledged a lack of business direction resulting in a $68 \%$ failure to implement organizational strategies. Through a multiple case study, we aimed to explore the human capital strategies utilized in the automotive and food service industries to reduce voluntary employee turnover. We analyzed the responses of twenty-four service leaders in the Eastern and Midwest regions of the United States through the process of compiling, disassembling, reassembling, interpreting, and concluding. Vroom's expectancy theory and G.S. Becker's human capital theory provided the conceptual framework for the study. Five emergent themes supported positive work relationships with employees through employee motivation, employee selection, and employee incentives: benchmarking, training, communication strategies, organizational change, and integrity. The results support employee development and improved corporate profitability, which increases competitive advantage and economic sustainability within the service industry.
\end{abstract}

Keywords: Employee engagement, Human capital, Organizational behavior, Organizational change, Succession planning, Workplace solutions

\section{ARTICLE INFORMATION \\ Author(s): Olivia Patrice Chante' Miller, Regina Banks-Hall Received 27 Aug 2020; Accepted 11 Sep 2020; Published 25 Sep 2020; e-ISSN: 2347-4696; \\ Paper Id: BMN-IJBMR-2020-6; \\ Citation: -- \\ Webpage-link: \\ https://ijbmr.forexjournal.co.in/archive/volume-8/ijbmr-080304.html}

\section{INTRODUCTION}

Industries often face organizational change associated with technology, economic climate, and global competition. The increase of organizational change has created the need for clear leadership and investment in best practice solutions that (a) engage employees, (b) improve operational performance, and (c) reduce manufacturing costs [1] Ineffective leadership strategies may impact business sustainability, viability, and profitability. Therefore, it is essential for business leaders to stay abreast of emerging trends, research, and innovation methods.

Multinational chief executives acknowledged a majority of their organizational change initiatives are ineffective, indicating a problem with strategy execution or implementation [2]. Chief executives associated $70 \%$ of the failure with coordination among business units and misaligned initiatives with its mission [3]. The lack of business direction leads to a decrease in profitability and a reduction in business growth [4]. For multinational chief executives, the challenge may be some automotive manufacturing senior leaders do not have a set of best practice solutions to help front-line leaders execute business strategies.

With revenues of approximately $\$ 1.7$ billion, the food service industry accounts for the employment of over 12.9 million workers in the United States [5]. Researchers identified that the food service industry contributes to economic growth in the United States; however, voluntary employee turnover is a growing concern [6]. Some food service leaders lack awareness of human capital, which increases the likelihood of increased voluntary employee turnover [7]. Griffith, Baur, and Buckley [8] added that it is vital for leaders to develop an effective plan to reduce organizational profit losses.

\subsection{Conceptual Framework}

We used Vroom's expectancy theory, Becker's human capital theory, and Herzberg's two-factor theory as the conceptual framework. Vroom's thesis focused on the idea that employee performance was attached to (a) personality, (b) skill, (c) performance, (d) knowledge, and (e) abilities. As applied to an organizational setting, Vroom's theory was appropriate for studying how automotive and food service leaders use best practice solutions for enhancing employee work performance. The expectancy theory's premise concluded that while 
employees have different goals, they can be motivated if they believe a positive correlation exists between effort and performance.

Becker's human capital theory [9] indicated that education and training increase employees' knowledge and skills, which in turn increases advancement opportunities and pay opportunities. Becker [10] later expanded his study to show that increasing employee knowledge and skills lead to increased employee compensation, directly impacting employee turnover intentions. Satisfied employees tend to stay with organizations for more extended periods than dissatisfied employees [11].

Herzberg [12] focused on motivation factors divided between intrinsic (internal) and extrinsic (external) motivators (as cited in Robinson, 2010). Herzberg [12] identified achievement, recognition, and promotion as motivators, and supervision, salary, and work environment as hygiene factors. Herzberg's pioneering approach mentioned that motivators are also known as intrinsic factors, and hygiene is also known as extrinsic factors.

\section{LITERATURE REVIEW}

\subsection{Organizational Change}

A significant challenge for organizations is developing a culture, climate, and set of workplace solutions supporting (a) re-engineering, (b) managing global competition, and (c) embracing new technologies [13]. Organizational change is modifying existing work routines and strategies that affect the whole organization [14]. Kump [15], emphasized that $68 \%$ of all organizational change strategies fail to deliver expected results or meet specific objectives. The failure of a strategic direction by automotive manufacturing senior leaders may define employees' resistance to support a strategy and adopt necessary behaviors that accomplish the organization's strategic mission [16].

\subsection{Succession Planning}

Succession planning is the systematic long-term process in which leaders transfer responsibilities, knowledge, and roles to meet organizational needs [17]. Succession planning involves (a) selecting and training employees, (b) the development of a mission or vision for the organization, (c) defining roles of employees, and (d) communicating decisions to stakeholders [18]. Poornima, Sutha, and Perera [19] noted that effective succession planning decreases employee recruitment costs and increases employee retention. Therefore, organizations must proactively monitor the needs of the company to recruit and retain employees effectively.

\subsection{Motivation}

Highly motivated employees are more likely to work enthusiastically, which increases productivity and efficiency. Front-line employees may work extremely hard to support the organization's goals or produce mediocre workloads to earn their wages. Thus, a strategy for organizational leaders is to maximize (a) knowledge, (b) skills, (c) and abilities to obtain the best performance [20]. Based on the importance of employee motivation, Krajcsák [21] considered workplace motivation a core competency of leadership. Understanding employee motivation helps automotive manufacturing leaders develop a work environment that (a) rewards teams, (b) business divisions, and (c) corporate performance [22].

\subsection{Replacement Costs}

Replacement costs could be a challenge for leaders in the service industry. Dwesini [23] indicated that voluntary employee turnover increases labor costs and decreases organizations' profitability. Giao et al. [24] emphasized that voluntary employee turnover costs for service organizations range from 50 to $200 \%$ of an employee's salary. Indirect costs, such as organizational productivity and employee satisfaction, account for $70-85 \%$ of total annual costs, which results in loss of corporate profitability [25]. Direct costs, such as employee replacement costs, training of newly hired employees, and advertising costs for new positions, can cost organizations $21 \%$ of the total annual cost [26].

\subsection{Engagement}

Paek, Schuckert, Kim, and Lee [27] emphasized that employee engagement is based on employee morale and job satisfaction. Employee engagement in the food service industry creates an organizational culture based on leaders and followers collectively reaching organizational goals [28]. O'Connor and Crowley-Henry [29] added that employee engagement significantly relates to employees' job satisfaction, turnover rates, and work behaviors. To support this idea, Shahpouri, Namdari, and Abedi [30] mentioned that self-efficacy, organizational self-esteem, performance feedback, and support systems could affect employees' work engagement.

\subsection{Leadership}

The role of leadership defines organizational behavior associated with the leader's ability to influence employee behavior [31]. Several researchers emphasized the importance of communication to drive organizational profitability and promote a positive work environment. Ruben and Gigliotti [32] emphasized that effective leadership involves clear communication, which influences employee behavior. Osman, Noordin, Daud, and Othman [33] added that leaders who 
communicate clear job expectations and give constructive feedback develop positive relationships.

Accordingly, leaders are catalysts for change and have the capacity to enhance, maintain, or hinder employee performance based on their leadership abilities. Additionally, the concept of ethical leadership influences employees' attitudes toward organizations. Demirtas and Akdogan, [34] indicated ethical leadership can affect employees' intentions to stay with or leave organizations. Dhar [35] added that ethical leadership improves the behavior of employees.

Moslehpour, Altantsetseg, Mou, and Wong [36], suggested leadership facilitates processes important in fostering (a) supportive work climates, (b) positive employee attitudes, and (c) commitment to organizational change. Wilson-Wünsch, Beausaert, Tempelaar, and Gijselaers [37] confirmed that leaders' knowledge and experience are a significant factor in the food service industry's organizational performance. Sipe [38] added that experienced leaders promote new ideas within organizations, which increases employee empowerment.

\section{Research Methods}

We used the qualitative multiple case study methodology. Participants shared their knowledge and experiences regarding human capital strategies, and common themes emerged from their responses. Unlike the mixed method or quantitative method, the qualitative method allowed us to thoroughly explore the phenomenon by asking probing questions of leaders in the automotive and food service industry.

\subsection{Data Collection}

Data collection consisted primarily of face-to-face semistructured interviews. Data saturation was reached with twenty-four participants in the automotive and food service industries. To enhance the reliability and validity, we included member checking by providing each participant with a summary of the interview to verify we understood the responses' intent. Member checking allows participants an opportunity to verify the accuracy of the interview interpretation [39].

\subsection{Data Collection Instrument}

For the purpose of this study, the researchers served as data collection instruments. Wasiu, Olubukunola, Akinlolu, and Oluwatosin [40] mentioned in qualitative research, researchers may serve as the data collection instrument when conducting interviews. We started the process by transcribing all participant interviews. Files were recorded using a data recorder and after each interview was completed, copied to a zip drive for additional storage and protection. We kept the confidentiality of all participants by using an alphanumeric coding system. Additionally, we used member checking to enhance the quality of our study. This process also supported data saturation by ensuring no additional new information is received.

\section{RESULTS}

\subsection{Emergent Themes}

We used alphanumeric codes to protect the confidentiality of the participants. After completing each interview, we added study data collected from the participants to the data analysis program to compare with previously coded data, which helped identify critical themes to answer the overreaching research questions. Based on the findings of the research collected, the following five themes emerged: (a) benchmarking, (b) training, (c) communication strategies, (d) change management, and (e) integrity.

\subsubsection{Benchmarking}

Participants emphasized the need for knowledge and skills when implementing and creating business processes throughout the organization. Participants saw benchmarking as a key to successful strategy execution and employee engagement. Benchmarking is a technique that allows for a continuous and systematic process that confronts effectiveness measured by (a) productivity, (c) quality, and (c) experience with organizations considered models of perfection.

\subsubsection{Training / Selection}

Employee training is a key business strategy and support of additional research related to an employee's expectancy of rewards within the workplace. Lee, Keil, and Wong [41] suggested employee training improves key workplace outcomes benefiting employees. Some participants believed that procedures for training could be developed into successful best practice solutions. A key recommendation supported the creation of a training center and considered it strategic to creating solutions that benefited employee development. Another key training process identified was on-the-job training because on-the-job training helps identify skill sets and allows an effective method for cross-training. On-the-job training can also identify employees for leadership and succession planning.

Another critical function of training is goal setting. Goal setting strengthens (a) skill sets, (b) knowledge, and (c) abilities. Goal setting affects valence because it motivates and regulates behaviors to achieve more valued outcomes [42]. Participants also provided information on the impact of group training, as it related to goal setting. Participants added that group-level activities should include (a) communication training, (b) employee interactions, (c) coaching, and (d) mentorship. Participants recommended additional investment in training for employees, senior leaders, and CEOs. Participants considered partnerships with other departments and key organizational leaders could be used as another 
approach to measure (a) best practice solutions, (b) employee growth, and (c) organizational success.

Training aligned with the literature review, by focusing on the impact of employee motivation and workplace expectancy. Expectancy refers to a service leader's perception of their role in improving their performance [43]. These improvements are determined by self-efficacy, goal difficulty, and perceived control in their ability to perform their job duties. The demands of senior leaders require more than work assignments and focus on areas such as leading organizational change and developing relationships with other employees that encourage (a) commitment, (b) teamwork, and (c) collaboration.

\subsubsection{Communication}

Effective communication plays a significant role in employee engagement and motivation [44]. Effective communication strategies increase employee success when systems include clear direction, planning, stakeholder identification, and employee goals [45]. To achieve an effective communication strategy, each front-line manager must understand its goals and how their efforts tie into the company's mission for success [46]. Communication is essential for organizational success, and without it, motivation, leadership, and productivity cannot survive [46].

Participants shared information about the impact of the leader's verbal statements and their actions about creating effective communication strategies for employees. When a leader's verbal communication differs from their workplace behavior, the leader's actions can hinder (a) employee motivation, (b) empowerment, and (c) commitment to organizational goals [46]. Participants believed weekly briefings provided an opportunity to share workplace issues, corporate objectives, and employee praise.

Participants also believed written communication, through memos and policy procedures, confirmed or reinforced information provided weekly or in other informal settings.

However, participants acknowledged that communication was critical and challenging due to the nature of the environment. The communication of corporate procedures, whether verbal or written, could be affected by key business factors, explanations, interpretations, acceptance, or rejection.

The final area for communication strategies, centered on the relationship between management and employees as it related to communication and workplace interaction. Dinh [47] acknowledged that employees considered interaction with immediate supervisors the most stressful aspect of their job duties. Participants stress the impact of ethics and leadership when communicating business strategies. Participants believed that leaders can share information accurately and offer employees an opportunity for clarification, employees are less likely to make mistakes [48].

\subsubsection{Change Management}

The interaction between management and employees is often a factor that hinders or improves organizational strategies [49]. Understanding why employees resist change and why change initiatives fail is essential when crafting best practice solutions. Participants suggested a key reason for organizational change initiatives' failure was due to an employee's resistance to change. Participants believed employees resisted change for several reasons and included: (a) distrust in management, (b) fear of unemployment, (c) and the inability to understand new technology or a corporate culture that creates a mindset of "us against them."

Participants felt a best practice solution that supported improvements in working relationships could strengthen the workplace. Best practices through successful implementation can be used as a successful method for modifying an organizational culture. Participants also discussed the impact of transformational leadership, believing leaders are catalysts for change and have the capacity to enhance employee performance with their leadership abilities.

When aligning this theme with the research question, participants focused on the impact leadership and organizational change have on employee expectancy. When a strong working relationship exists, employees can expect (a) support, (b) resources, (c) training, and (d) leadership from management. When there is no clear working relationship, employees respond to management, based on their perceived understanding of management responsibilities. This response can create a positive or negative impact based on the front-line manager's knowledge of duties and the perceived benefits they will receive based on the change policy.

\subsubsection{Integrity}

Ethical leadership within organizations is considered a vital component when making an organizational change or implementing strategies [50]. Leaders who are authentic impact the engagement of employees [51]. Participants believed leaders had an influential role in enhancing employee engagement. According to Zhu and Zhang [52], leadership describes organizational behavior associated with the leader's ability to impact employee behavior.

Palanski, Cullen, Gentry, and Nichols [53] noted that integrity in the face of adversity could be viewed as a critical characteristic of inspirational leadership. Employees who display enthusiasm in completing their duties reveal a strong bond between employee and leader. Leaders aid in this area by being transparent in their decision making. When employees lose trust in leaders, the bond created that supports organizational goals is broken. When applying this theme to the research, question front-line and food service leaders may have an expectancy of trust by management as it relates to their job duties and benefits. Any potential flaws with integrity can violate trust and hinder the completion of organizational goals. 


\section{CONCLUSION}

Organizational change is a process that occurs over time; success is often found in the lack of safety of a system, creating a need for survival in an environment under constant economic change [14]. Prior research supports a theory that voluntary employee turnover is problematic within the service industry when leaders fail to implement human capital strategies. Other findings suggested that leaders' lack of business direction supported a $68 \%$ failure rate in implementing workplace solutions [15]. The study's significance revealed workplace solutions for service industries, supported enhancements in employee motivation, succession planning, and profitability.

Vroom's expectancy theory [54] and G.S. Becker's human capital theory [9] supported a correlation to the study's emergent themes that investments in education, employee motivation, and training were crucial strategies for maintaining profitability for service industry leaders. The implementation of these strategies can lead to modifications in service industry leaders' success. Organizational leaders may use this multiple case study findings as a resource to understand the importance of strategic initiatives. Particularly, leaders in the service industry may use the research findings to increase their awareness of social responsibility related to voluntary employee turnover intentions.

The study's findings revealed strategies for service leaders related to the creation of best practice solutions when helping their employees execute organizational strategies. Five themes emerged from the study findings for best practice solutions (a) benchmarking, (b) training, (c) communication strategies, (d) organizational change, and (e) integrity. The findings provide a blueprint to build sustainable models for developing best practice solutions by service leaders when helping employees execute organizational strategies. The information can be shared within other geographical areas to help service managers support profitability, sustainability, and business growth.

\section{REFERENCES}

[1] Sumanasiri, A. (2020). Leadership Dimensions Influencing Sustainability Leadership in Sri Lanka: Mediating Effect of Managers' Ethical Behavior and Organizational Change. J. Mgmt. \& Sustainability, 10, 113.

[2] Fragouli, E., \& Nicolaidou, Z. (2020). Risk Management of Multinational Companies (MNCs) in Rising Economies. International Journal of Information, Business and Management, 12(4), 237-267.

[3] Sull, D., Homkes, R., \& Sull, C. (2015). How conventional wisdom derails strategy execution: interaction. Harvard Business Review, 93, 16.

[4] Hilorme, T., Perevozova, I., Shpak, L., Mokhnenko, A., \& Korovchuk, Y. (2019). Human capital cost accounting in the company management system. Academy of Accounting and Financial Studies Journal, 23, 1-6.
[5] Joung, H., Goh, B. K., Huffman, L., Yuan, J. J., \& Surles, J. (2015). Investigating relationships between internal marketing practices and employee organizational commitment in the foodservice industry. International Journal of Contemporary Hospitality Management, 27, 1618-1640.

[6] Choper, J., Schneider, D., \& Harknett, K. (2019). Uncertain Time: Precarious Schedules and Job Turnover in the US Service Sector. Washington Center for Equitable Growth Working Paper.

[7] Lee, M. C. C., Idris, M. A., \& Tuckey, M. (2019). Supervisory coaching and performance feedback as mediators of the relationships between leadership styles, work engagement, and turnover intention. Human Resource Development International, 22(3), 257-282.

[8] Griffith, J. A., Baur, J. E., \& Buckley, M. R. (2019). Creating comprehensive leadership pipelines: Applying the real options approach to organizational leadership development. Human Resource Management Review, 29(3), 305-315.

[9] Becker, G. S. (1964). Human capital. New York, NY: Columbia University Press.

[10] Becker, G. S. (1975). Human capital: A theoretical and empirical analysis with special reference to education. New York, NY: National Bureau of Economic Research.

[11] Tongchaiprasit, P., \& Ariyabuddhiphongs, V. (2016). Creativity and turnover intention among hotel chefs: The mediating effects of job satisfaction and job stress. International Journal of Hospitality Management, 55, 33-40.

[12] Herzberg, F. (1974). Motivation-hygiene profiles: Pinpointing what ails the organization. Organizational Dynamics, 3(2), 1829.

[13] Eketu, C. A. (2019). Organizational Change Management as resilient seeking behavior of the firm. International Journal of Research in Commerce and Management Studies, 1(2), 26-37.

[14] Zimmerman, R. D., Swider, B. W., \& Arthur, J. B. (2020). Does turnover destination matter? Differentiating antecedents of occupational change versus organizational change. Journal of Vocational Behavior, 103470.

[15] Kump, B. (2019). Beyond power struggles: A multilevel perspective on incongruences at the interface of practice, knowledge, and identity in radical organizational change. The Journal of Applied Behavioral Science, 55(1), 5-26.

[16] Shalender, K., \& Yadav, R. K. (2019). Strategic flexibility, manager personality, and firm performance: The case of Indian Automobile Industry. Global Journal of Flexible Systems Management, 20(1), 77-90.

[17] Ali, Z., \& Mehreen, A. (2019). Understanding succession planning as a combating strategy for turnover intentions. Journal of Advances in Management Research.

[18] Javed, B., \& Jaffar, M. (2019). Impact of Succession Planning on Employee Retention.

[19] Poornima, W. A. D. N., Sutha, J., \& Perera, K. J. T. (2019). Impact of Effective Succession Planning Practices on Employee's Retention (With Special Reference to Private Business Organizations in Sri Lanka).

[20] Hwang, M. I. (2019). Relationship between teamwork and team performance: Experiences from an ERPsim competition. Journal of Information Systems Education, 29(3), 4. 
[21] Krajcsák, Z. (2019). Leadership strategies for enhancing employee commitment in TQM. Journal of Management Development.

[22] Neirotti, P. (2020). Work intensification and employee involvement in lean production: New light on a classic dilemma. The International Journal of Human Resource Management, 31(15), 1958-1983.

[23] Dwesini, N. F. (2019). Causes and prevention of high employee turnover within the hospitality industry: A literature review. African Journal of Hospitality, Tourism and Leisure, 8(3), 1-15.

[24] Giao, H. N. K., Vuong, B. N., Huan, D. D., Tushar, H., \& Quan, T. N. (2020). The Effect of Emotional Intelligence on Turnover Intention and the Moderating Role of Perceived Organizational Support: Evidence from the Banking Industry of Vietnam. Sustainability, 12(5), 1857.

[25] Ansari, F. U. (2020). The Impact of Profitability, Leverage, Efficiency and Liquidity on Return on Equity: The Case of Indian IT Companies. IUP Journal of Accounting Research \& Audit Practices, 19(2), 23-34.

[26] Roche, M. A., Duffield, C. M., Homer, C., Buchan, J., \& Dimitrelis, S. (2015). The rate and cost of nurse turnover in Australia. Collegian, 22, 353-358.

[27] Paek, S., Schuckert, M., Kim, T. T., \& Lee, G. (2015). Why is hospitality employees' psychological capital important? The effects of psychological capital on work 122 engagement and employee morale. International Journal of Hospitality Management, 50, 9-26.

[28] Tannady, H., Tannady, H., \& Zami, A. (2019). The Effect of Organizational Culture and Employee Engagement on Job Performance of Healthcare Industry in Province of Jakarta, Indonesia. Calitatea, 20(169), 18-22.

[29] O'Connor, E. P., \& Crowley-Henry, M. (2019). Exploring the relationship between exclusive talent management, perceived organizational justice and employee engagement: Bridging the literature. Journal of Business Ethics, 156(4), 903-917.

[30] Shahpouri, S., Namdari, K., \& Abedi, A. (2016). Mediating role of work engagement in the relationship between job resources and personal resources with turnover 130 intention among female nurses. Applied Nursing Research, 30, 216-221.

[31] Zhao, H., \& Zhou, Q. (2019). Exploring the impact of responsible leadership on organizational citizenship behavior for the environment: A leadership identity perspective. Sustainability, 11(4), 944.

[32] Ruben, B. D., \& Gigliotti, R. A. (2016). Leadership as social influence: An expanded view of leadership communication theory and practice. Journal of Leadership \& Organizational Studies, 23, 467-479.

[33] Osman, I., Noordin, F., Daud, N., \& Othman, M. Z. (2016). The dynamic role of social exchange and personality in predicting turnover intentions among professional workers. Procedia Economics and Finance, 35, 541-552.

[34] Demirtas, O., \& Akdogan, A. A. (2015). The effect of ethical leadership behavior on ethical climate, turnover intention, and affective commitment. Journal of Business Ethics, 130, 59-67.

[35] Dhar, R. L. (2015). The effects of high performance human resource practices on service innovative behaviour. International Journal of Hospitality Management, 51, 67- 75.

[36] Moslehpour, M., Altantsetseg, P., Mou, W., \& Wong, W. K. (2019). Organizational climate and work style: The missing links for sustainability of leadership and satisfied employees. Sustainability, 11(1), 125.

[37] Wilson-Wünsch, B., Beausaert, S., Tempelaar, D., \& Gijselaers, W. (2015). The making of hospitality managers: The role of knowledge in the development of expertise. Journal of Human Resources in Hospitality \& Tourism, 14, 153-176.

[38] Sipe, L. J. (2016). How do senior managers influence experience innovation? Insights from a hospitality marketplace. International Journal of Hospitality Management, 54, 75-83.

[39] Sechelski, A. N., \& Onwuegbuzie, A. J. (2019). A call for enhancing saturation at the qualitative data analysis stage via the use of multiple qualitative data analysis approaches. The Qualitative Report, 24(4), 795-821.

[40] Wasiu, O. A., Olubukunola, O., Akinlolu, G. O., \& Oluwatosin, A. (2015). Obesity indices as predictors of pattern of selfreported arthritis among elderly women in 137 Southwestern Nigeria. SAGE Open Medicine, 3(2015).

[41] Lee, J. S., Keil, M., \& Wong, K. E. (2015). The effect of goal difficulty on escalation of commitment. Journal of Behavioral Decision Making, 28, 114-129.

[42] Lyons, P., \& Bandura, R. (2019). Self-efficacy: core of employee success. Development and Learning in Organizations: An International Journal.

[43] Supatn, N., \& Puapradit, T. (2019). Roles of expectancy on employee engagement and job performance. JABS, 5(2), 88-98.

[44] MacDonald, P., Kelly, S., \& Christen, S. (2019). A path model of workplace solidarity, satisfaction, burnout, and motivation. International Journal of Business Communication, 56(1), 31-49.

[45] Men, L. R., \& Yue, C. A. (2019). Creating a positive emotional culture: Effect of internal communication and impact on employee supportive behaviors. Public relations review, 45(3), 101764.

[46] Holmes, W. T., \& Parker, M. A. (2017). Communication: Empirically testing behavioral integrity and credibility as antecedents for the effective implementation of motivating language. International Journal of Business Communication, 54(1), 70-82.

[47] Dinh, L. (2020). Determinants of employee engagement mediated by work-life balance and work stress. Management Science Letters, 10(4), 923-928.

[48] Andersson, R. (2019). Employee communication responsibility: Its Antecedents and implications for strategic communication management. International Journal of Strategic Communication, 13(1), 60-75.

[49] Grama, B., \& Todericiu, R. (2016). Change, resistance to change and organizational cynicism, Studies in Business and Economics, 11, 47-54.

[50] Shakeel, F., Kruyen, P. M., \& Van Thiel, S. (2019). Ethical leadership as process: A conceptual proposition. Public Integrity, 21(6), 613-6.

[51] McAuliffe, N., Bostain, N. S., \& Witchel, A. D. (2019). The relationship between authentic leadership, trust, and engagement in library personnel. Journal of Library Administration, 59(2), 129-148.

[52] Zhu, C., \& Zhang, F. (2020). How does servant leadership fuel employee innovative behavior? A moderated mediation framework. Asia Pacific Journal of Human Resources, 58(3), 356-377. 
[53] Palanski, M., Cullen, K., Gentry, W., \& Nichols, C. (2015). Virtuous leadership: Exploring the effects of leader courage and behavioral integrity on leader performance and image. Journal of Business Ethics, 132, 297-310.

[54] Vroom, V. H. (1964). Work and Motivation. New York, NY: McGraw-Hill.

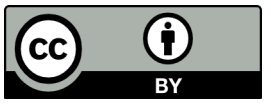

(C) 2020 by the Olivia Patrice Chante' Miller and Regina Banks-Hall. Submitted for possible open access publication under the terms and conditions of the Creative Commons Attribution (CC BY) license (http://creativecommons.org/licenses/by/4.0/). 